Revista de Derecho

de la Pontificia Universidad Católica de Valparaíso

LIV (Valparaíso, Chile, 1er semestre de 2020)

[pp. $151-181]$

\title{
RECOMENDACIONES Y PROPUESTAS PARA UNA REFORMA PENITENCIARIA. APUNTES PARA SU SISTEMATIZACIÓN Y DELIMITACIÓN*
}

[Recommendations and proposals for a Penitential Reform. Notes for your systematization and delimitation]

\author{
Mario Durán Migliardi** \\ Gabriela Prado Prado***
}

\begin{abstract}
RESUMEN
El objetivo principal del presente trabajo es realizar una propuesta de sistematización y de delimitación de las principales recomendaciones, sugerencias o propuestas de mejoras que, orientadas a la reforma del sistema penitenciario, han realizado en las últimas décadas tantos organismos internacionales, comisiones especiales y la doctrina especializada. Para ello, luego de introducir al tema y delimitar los objetivos del trabajo, se presentará una sistematización de la normativa internacional y de las recomendaciones, directrices y reglas de Naciones Unidas en materia penitenciaria.
\end{abstract}

\begin{abstract}
The main objective of this work is to make a proposal for systematization and delimitation of the main recommendations, suggestions or proposals for improvements that international organizations, special commissions and the doctrine have made in recent decades, aimed at the reform of the penitentiary system specialized. To do this, after introducing the topic and defining the objectives of the work, a systematization of international regulations and recommendations, guidelines and rules of the United Nations in prison matters will be presented.
\end{abstract}

* Este trabajo ha sido realizado en el marco del Proyecto Interno de Investigación de la Universidad de Atacama, DIUDA n 17/7, titulado "Diseño orgánico-funcional de un Derecho penitenciario orientado a fines preventivos y resocializadores. Análisis y sistematización de sus principales elementos" de quien los autores son investigador responsable y co-investigadora, respectivamente.

** Doctor en Derecho, Universidad de Salamanca. Profesor Titular, Departamento de Ciencias Jurídicas. Universidad de Atacama, Copiapó, Chile. Correo electrónico: mario.duran@uda.cl

*** Doctora en Derecho, Universidad de Salamanca. Profesora Asociada, Departamento de Ciencias Jurídicas. Universidad de Atacama, Copiapó, Chile. Correo electrónico: gabriela.prado@uda.cl 
Posteriormente, se ofrecerá una sistematización de aquellas propuestas de mejoras realizadas por comisiones especiales y por la doctrina especializada, tanto en nuestro país como en países de nuestro entorno cultural. En ambos casos, se intentará delimitar entre los distintos aspectos de la política pública penitenciaria. Todo ello a través del análisis dogmático y comparativo de normativas y propuestas. Finalmente, se presentará algunas ideas a manera de conclusión.

\section{Palabras clave}

Derecho Penitenciario - reforma penitenciaria - ejecución de la pena Derechos Humanos.
Subsequently, a systematization of those proposals for improvements made by special commissions and by specialized doctrine will be offered, both in our country and in countries of our cultural environment. In both cases, an attempt will be made to delimit between the different aspects of prison public policy. All this through the dogmatic and comparative analysis of regulations and proposals. Finally, some ideas will be presented as a conclusion.

\section{KEYWORDS}

Prison law - prison reform - execution of the sentence - Human Rights.

Recibido el 20 de marzo de 2020 y Aprobado el 2 de junio de 2020.

\section{INTRODUCCIÓN Y DELIMITACIÓN DE OBJETIVOS.}

En los últimos años, desde distintos ángulos, realidades y perspectivas, nuevamente se ha puesto de manifiesto la necesidad y relevancia de una reforma al conjunto de normas, principios y disposiciones conocidos como Derecho penitenciario. Curiosamente, esta urgente necesidad, aunque parte desde perspectivas totalmente opuestas, comparte un similar diagnóstico, esto es, lo insostenible que resulta la mantención del sistema penitenciario tal cual lo conocemos hasta este momento.

Por ello es que, tanto desde la terrible y cruda realidad carcelaria que nos presentan aquellos sistemas penitenciarios aún basados en el fin retributivo y en el cumplimiento efectivo de penas restrictivas de libertad, así como de los permanentes y nuevos desafíos técnicos, de infraestructura y humanos que se producen en los sistemas penitenciarios orientados a la prevención y la resocialización del condenado, el juicio crítico y de insatisfacción es similar. En ambos, con sus particularidades y diferencias, surgen un cuestionamiento similar: ¿cómo recuperamos, mejoramos o corregimos el sistema penitenciario?. Así, al surgir desde distintos ángulos, realidades o perspectivas, el problema no sólo se presenta en países que no tienen un gran desarrollo normativo del área jurídico penitenciaria, como el nuestro o en países con recientes incorporaciones normativas en estas materias sino también en Estados con una larga tradición jurídica en tales materias, 
como Italia ${ }^{1}$ y España ${ }^{2}$. Países donde también están bregando por nuevas reformas para su Derecho penitenciario, se discute sobre el contenido de la fase de ejecución de la pena y, en especial, sobre la función de la pena privativa de libertad ${ }^{3}$.

Esta heterogeneidad en el punto de partida, implica que, para algunos, la necesidad de tal reforma penitenciaria venga dada por la urgencia de evitar la cada vez más creciente desnaturalización del Derecho penitenciario, no ya por la vieja polémica de su vínculo con el Derecho administrativo, sino más bien por los intentos de colonización por parte de un Derecho penal sustantivo que, cada vez más expansivo e invasivo, tiende a desvirtuarlo a través de la inobservancia o reorientación de sus características y de sus principios estructurales ${ }^{4}$. Esto es, por la necesidad de impedir un nuevo proceso de desnaturalización penitenciaria que implica, por una parte, la destrucción o desmontaje del modelo penitenciario ideal, cuando existe, sino, por otra, la colonización de sus contenidos y fines, cuando el respectivo Derecho penitenciario no existe o se encuentra regulado por meras normas de rango jurídicamente inferior.

Para otros, la relevancia de una reforma correctiva estaría determinada por la creciente y constante incrustación de normas, procedimientos y fines, propios de un nuevo modelo o paradigma penitenciario que llegó para

${ }^{1}$ Sobre la reciente reforma penitenciaria en Italia, véase La Riforma dell'ordinamento penitenziario, Decreto legislativo 123 (2018); La vita detentiva e il laboro penitenziario, Decreto legislativo 124 (2018); L'esecuzione penale minorile, Decreto legislativo 121 (2018); Della Bella, Angela. Riforma dell'ordinamento penitenziario: le novità in materia di assistenza sanitaria, vita detentiva e lavoro penitenziario. Decreti legislativi 2 ottobre 2018, n. 123 e 124 (G.U. 26 ottobre 2018), en Diritto Penale Contemporaneo; Paccagnella Casari, Giorgia, La riforma dell'Ordinamento Penitenziario: soluzioni timide per problemi gravi, en Giurisprudenza Penale Web 3 (2019).

${ }^{2}$ Respecto de la reciente discusión para una reforma penitenciaria en España, Véase Mata y Martín, Ricardo, Apuntes sobre la esperada reforma penitenciaria, en Diario La ley 9516, Sección Doctrina, 12 de Noviembre de 2019; GÜERRI, Cristina, La reforma penitenciaria será con los funcionarios o no será. Acerca de la necesidad de contar con el personal para lograr el cambio en la institución penitenciaria, en Papers 104 (2019), 3, pp. 553-559.

${ }^{3}$ En este sentido, Mapelli Caffarena, Borja, Capitulo 1. Concepto y ámbito del Derecho penitenciario, en MAPelli, Borja - CAAMaÑo, Cristina - Espinoza, Olga, Ejecución de la pena privativa de libertad: una mirada comparada, Colección Documento de Trabajo 17 (Madrid, EUROsociAL, 2014), pp. 24 y ss.

${ }^{4}$ Así, Gallego Díaz, Manuel, La desnaturalización del Derecho penitenciario por el Derecho penal: análisis de tres supuestos paradigmáticos en relación con el sistema de individualización cientifica, en ADPCP 69 (2016), pp. 39-74. En el mismo sentido, Baiguera Altieri, Andrea, Verso un nuovo Diritto Penitenziario, en Dirito.it (2019), pp. 1-10. 
quedarse, que han hecho involucionar a esta área del sistema jurídico penal hasta convertirlo en un verdadero Derecho penitenciario del enemigo 5 . Especialmente, en los casos en que, tanto el fin de la pena como el régimen de cumplimiento de penas privativas de libertad, queda reservado o se ve agravado sólo respecto a ciertos grupos de condenados o a determinada clase de delitos. Análisis al que, desde ya, se le puede definir, para algunos casos, como un claro llamado de atención frente a desviaciones o vulneraciones de derechos construidas a propósito de situaciones de emergencia y sostenidas o institucionalizadas en el tiempo. Pero que también, para otros casos, lamentablemente se le puede catalogar como una tesis meramente verificadora de las reales condiciones de desarrollo y existencia del respectivo Derecho penitenciario ${ }^{6}$.

Sin embargo, desde una perspectiva menos teórica, más práctica y concreta, se vincula la necesidad de una reforma penitenciaria a la constatación fáctica del grave problema actual de hacinamiento o sobrepoblación carcelaria ${ }^{7}$, cuestión que se plantea, además, como vivo ejemplo de la ineficiencia de la pena privativa de libertad, de los tradicionales programas asistenciales de reinserción social y de los sistemas retributivos en general.

Esta visión práctica del problema en cuestión, en principio visto como un simple efecto de la priorización económica de los siempre es-

${ }^{5} \mathrm{Al}$ respecto, Arribas López, Eugenio, Aproximación a un 'Derecho penitenciario del enemigo', en Revista de Estudios Penitenciarios 253 (2007), pp. 31-59; GIMBERNAT DíAz, Eva, El Derecho penitenciario del enemigo aplicable a los presos por delitos de terrorismo, en CuERDA RiEzu, Antonio, El Derecho penal ante el fin de ETA (Madrid, Tecnos, 2016), pp. 93-102.

${ }^{6}$ En este último sentido, Murillo Rodríguez, Roy, Modernas tendencias en el Derecho penitenciario. Las propuestas del "Derecho penitenciario minimo", el "Derecho penitenciario del enemigo" y las reformas del 2003 en el ordenamiento jurídico-penitenciario español (Getafe, Universidad Carlos III, Tesis doctoral, 2009), pp. 210-297; Cambronero Torres, Melissa, Derecho Penitenciario del enemigo: hacia un análisis politico-criminal del sistema penitenciario Costarricense (San Juan, Universidad de Costa Rica, Tesis de licenciatura en derecho, 2014), pp. 111 y ss.

${ }^{7} \mathrm{Al}$ respecto, véase González Sánchez, Ignacio, Aumento de presos y Código Penal: una explicación insuficiente, en Revista Electrónica de Ciencia Penal y Criminología 13-04 (2011), pp. 04:1-04:22; Dolcini, Emilio, La «nueva» reincidencia. La cárcel en Italia se vuelve todavía más selectiva, en GARCía VALDÉs, Carlos-ET AL, Estudios penales en homenaje a Enrique Gimbernat (Madrid, Edisofer, 2008), I, pp. 829-861; DAMMERT, Lucia - ZuNigA, Liza, La cárcel: problemas y desafíos para las américas (Santiago, FLACSO, 2008), pp. 43-83; MATTHEWs, Roger, Una propuesta realista de reforma para las prisiones de Lationamérica, en Política criminal 6 (2011), 12, pp. 296-338, especialmente pp. 302-309; Noel Rodríguez, María, Hacinamiento penitenciario en América Latina: causas y estrategias para su reducción (México D.F., Comisión Nacional de los Derechos Humanos de México, 2015), pp. 13 y ss. 
casos recursos públicos, como una mala o negligente administración de los establecimientos penitenciarios o, en fin, como un simple tema de distribución de la población carcelaria, ha dado paso a una visión crítica más general y permanente sobre el problema penitenciario, que va más allá de la circunstancial y coyuntural política pública penitenciaria del gobierno de turno. Esto es, ver que el evidente y dramático hacinamiento o sobrepoblación carcelaria, generalizado en los Estados de nuestro entorno cultural, y en todo aquél que basa su sistema carcelario principalmente en la aplicación de la pena privativa de libertad, con carácter retributivo y como vía principal de sanción penal ${ }^{8}$, es un síntoma de un problema más esencial y profundo que entronca más bien con la corrección, mejora o reforma que debe realizarse del Derecho Penitenciario en el respectivo sistema jurídico penal que lo acoge, con su concepto, su rol y los fines que se le pretendan atribuir.

Vinculado también a la realidad y a la praxis del sistema penitenciario, se plantea la necesidad de ciertas mejoras, adecuaciones o reformas que hagan posible o más cercana la aplicación práctica de los principios limitadores del ius puniendi más próximos a este, esto es, el principio de proporcionalidad de la pena y el principio de humanidad o dignidad humana. Ideal que se concreta en lo que genérica y eufemísticamente se denomina; mejoras de las condiciones carcelarias. Las que, como bien resume Binder, constituyen el "contenido concreto de la pena". Por lo que, cuando hablamos de ellas "estamos hablando de la pena misma, no de algo agregado a ella. La Justificación de la pena -si ello es posible- es la justificación de las condiciones carcelarias concretas, no de una entidad distinta a ellas. También, cuando decimos que la pena debe ser proporcional al daño causado, lo que estamos diciendo es que las condiciones carcelarias deben ser proporcionadas al daño causado. Debe quedar claro: no existe la pena de prisión por fuera de las condiciones carcelarias" . Por ello, la constatación de los

\footnotetext{
${ }^{8} \mathrm{Al}$ respecto, Comisión Nacional De Los Derechos Humanos, La sobrepoblación en los centros penitenciarios de la República Mexicana. Análisis y pronunciamiento (México D.F., 2015), pp. 1-86; Arenas, Lorena - Cerezo, Ana, Realidad penitenciaria en Colombia: la necesidad de una nueva politica criminal, en Revista Criminalidad 58 (2016), 2, pp. 175-195; Magan Zeballos, Julio, La sobrepoblación en el sistema penitenciario peruano, en International Review of the Red Cross 903 (2017), pp. 1-7; Roca De Agapito, Luis, La masificación de las cárceles: Breve reflexión a propósito del caso de los Estados Unidos de América, en Revista Electrónica de Ciencia Penal y Criminología 19-07 (2017), pp.1-33; Instituto Nacional De Derechos HumaNOS, Estudio de las condiciones carcelarias en Chile. Diagnóstico del cumplimiento de los estándares internacionales de Derechos Humanos sobre el derecho a la integridad personal 2016-2017 (Santiago, INDH, 2018). pp. 30-52.

${ }^{9}$ Binder, Alberto, Introducción al Derecho penal (Buenos Aires, Ad-Hoc, 2004),
} 
negativos resultados y efectos sociales que históricamente se han obtenido con tales condiciones carcelarias -en particular a través de la pena privativa de libertad-, sobre todo cuando se desarrolla exclusivamente en el marco de una justificación retributiva de la pena, implica también abogar por una urgente reforma penitenciaria, como lo ha venido sosteniendo desde antiguo la Criminología ${ }^{10}$.

En el caso específico chileno, la necesidad de una reforma penitenciaria no sólo parte desde la base de una crítica al feble y parco sistema normativo existente en esta área ${ }^{11}$, o del evidente hacinamiento carcelario a que nos ha llevado el sistema imperante, aún bajo la aplicación de una reforma procesal penal de signo acusatorio ${ }^{12}$, sino sobre todo desde la visión crítica y negativa que se ha planteado tanto de la función que históricamente ha desarrollado en Chile el sistema carcelario ${ }^{13}$, del protagonismo de la

p. 304.

${ }^{10} \mathrm{Al}$ respecto, entre otros, véase, Melossi, Dario - PAVARInI, Massimo, Cárcel y fábrica. Los orígenes del sistema penitenciario. Siglos XVI-XIX (Buenos Aires, Siglo XXI, 1980); Bustos, Juan - Bergalli, Roberto - Miralles, Teresa, El pensamiento criminológico I. Un análisis crítico (Bogotá, Temis, 1983); BaratTA, Alessandro, Criminología crítica y crítica del Derecho penal. Introducción a la sociología jurídico penal (Buenos Aires, Siglo XXI, 2004); ZafFaroni, Eugenio, En busca de las penas perdidas (Buenos Aires, Ediar, 1989); Foucault, Michel, Vigilar y castigar. Nacimiento de la prisión (11 1 edición, Madrid, Siglo XXI, 1998); MATHIESEN, Thomas, Juicio a la prisión. Una evaluación crítica (Buenos Aires, Ediar, 2003); WACQUANT, Loïc, Castigar a los pobres: el gobierno neoliberal de la inseguridad social (Barcelona, Gedisa, 2010).

${ }^{11}$ Así, GuZmán, José Luis, Consideraciones críticas sobre el Reglamento Penitenciario chileno, en Gaceta Jurídica 168 (1994), pp. 12-17; CARnevali, Raúl - MaldoNADO, Francisco, El tratamiento penitenciario en Chile: especial atención a problemas de constitucionalidad, en Ius et Praxis 19 (2013), 2, pp. 385-418; Mañalich, Juan Pablo, El derecho penitenciario entre la ciudadanía y los derechos humanos, en Derecho y humanidades 18 (2011), pp. 163-178.

${ }^{12} \mathrm{Al}$ respecto, Cfr. DuCE, Mauricio - RIEGO, Cristián. La prisión preventiva en Chile: análisis de los cambios legales y su impacto (Santiago, Ediciones UDP, 2011); Duce, Mauricio - Riego, Cristián. Prisión preventiva y reforma procesal penal en América Latina. Evaluación y perspectivas (Santiago, CEJA-JSCA, 2015).

${ }^{13}$ En este sentido, entre otros, Álvarez, Andrés - Domínguez, Andrés (eds.), El sol en la ciudad: Estudios sobre prevención del delito y modernización penitenciaria (Santiago, Comisión Chilena de DDHH, 1993); PraDO, Francisco, La crisis en el sistema penitenciario chileno, en Revista Mensaje 503 (2001), pp. 50-52; Prado, Francisco, El sistema penitenciario chileno. Una aproximación crítica", en Revista Electrónica Agenda Pública 8 (2006), pp. 4 y ss.; MALdOnAdo, Mónica, Informe sobre los diversos problemas que afectan al funcionamiento del sistema carcelario en nuestro pais (2009); Castro, Álvaro, Sistema Penitenciario y Derechos Humanos, en Universidad Diego Portales, Informe Anual de Derechos Humanos Chile (Santiago, UDP, 2011), pp. 111-128; Altegrity Security Consulting, Sistema penitenciario chileno: el momento 
pena privativa de libertad ${ }^{14}$, así como de la política criminal penitenciaria realizada hasta la fecha en nuestro país ${ }^{15}$.

De esta forma, lo relevante es que, desde distintos ángulos, realidades o perspectivas, tanto la doctrina como organismos internacionales y organismos no gubernamentales, han puesto de manifiesto o recomendado la necesidad de producir determinados cambios o mejoras en los sistemas penitenciarios en general y respecto de determinadas áreas en particular. Cambios, recomendaciones o mejoras que, si se sistematizan y delimitan, si se clasifican y ordenan, pueden ayudar a aclarar y delimitar cuales son los puntos esenciales, su orden y prioridad, o incluso la manera e idoneidad de tales cambios o reformas.

Es en este contexto, entonces, que el objetivo del presente trabajo no es presentar diagnósticos ni estudios empíricos, sino realizar una propuesta de sistematización y de delimitación del conjunto de recomendaciones, sugerencias o propuestas de mejoras que, en materia de reforma penitenciaria, han realizado los principales organismos internacionales preocupados de

del cambio es ahora. Informe Final (Santiago, 2011); Instituto Nacional De DeReChos Humanos, Estudio de las condiciones carcelarias en Chile 2014-2015. Seguimiento de recomendaciones y cumplimiento de estándares internacionales sobre derecho a la integridad personal (Santiago, INDH, 2017); Instituto Nacional De Derechos Humanos, cit. (n. 8), pp. 30-52.

${ }^{14}$ En este sentido, Castro, Álvaro - Cillero, Miguel - Mera, Jorge, Derechos fundamentales de los privados de libertad. Guía práctica con los estándares internacionales en la materia (Santiago, UDP, 2010); Instituto Nacional De Derechos HumaNOS, Estándares internacionales en materia de personas privadas de libertad y condiciones de los centros penitenciarios: sistematización, análisis y propuestas (Santiago, INDH, 2012); Alcaíno, Eduardo, Derechos Humanos de los privados de libertad: las cárceles en chile: ¿avances o mantenimiento del status quo?, en UnIVERSIDAD Diego Portales, Informe Anual de Derechos Humanos Chile (Santiago, UDP, 2018), pp. 381-403; Arriagada, Isabel-Rochow, Diego, Privación de libertad en Chile: Desgobierno carcelario y afectación de derechos de la población penal, en Universidad Diego Portales, Informe Anual de Derechos Humanos Chile (Santiago, UDP, 2015), pp. 161-207.

${ }^{15} \mathrm{Al}$ respecto, Kendall, Stephen, Tutela judicial efectiva en la relación jurídica penitenciaria (Santiago, Librotecnia, 2010); STIPPELL, Jörg, Las cárceles y la búsqueda de una politica criminal para Chile. Un estudio acerca del acceso a la justicia, la violación de derechos y el nuevo proceso penal (Santiago, LOM, 2006); STIPPELL, Jörg, Cárcel, derecho y política (Santiago, LOM, 2013); DAMMERT, Lucia - DíAz, Javiera, Los desafíos del sistema carcelario en Chile (Caracas, CLACSO, 2004); DAMMERT, Lucia - DíAZ, Javiera, Cárceles privadas ¿modelo de gestión penitenciarias o inversión inmobiliaria?, en Observatorio 5 (2005), pp. 1 y ss.; SALINERO, Sebastián, ¿Por qué aumenta la población penal en Chile? Un estudio criminológico longitudinal', en Ius et Praxis 18 (2012), 1, pp. 113-150; Sanhueza, Guillermo - Pérez, Francisca, Cárceles concesionadas en Chile: evidencia empirica y perspectivas futuras a 10 años de su creación, en Politica Criminal 12 (2017), 24, pp. 1066-1084. 
estas materias, las comisiones especiales formadas en determinados Estados para tales efectos y la doctrina especializada.

Para ello, en primer lugar, se presentara una sistematización de las recomendaciones, directrices y reglas emanadas de la Organización de Naciones Unidas en materia penitenciaria, en cuanto normas vinculantes y de aplicación obligatoria para los Estados adherentes o suscriptores de las mismas. En segundo lugar, se ofrecerá una sistematización de aquellas propuestas de mejoras realizadas por la doctrina especializada o por comisiones especiales, tanto en nuestro país como en países de nuestro entorno cultural. Integrando en estas propuesta tanto aquellas recomendaciones realizadas por Organismos No Gubernamentales, no necesariamente vinculantes, como aquellas recomendaciones avaladas o patrocinadas por el respectivo Estado. En ambos casos, se intentará -en lo posible-, delimitar entre los aspectos claramente normativos e institucionales de la política pública penitenciaria, de los aspectos teleológicos o de fines, así como entre los aspectos intracarcelarios y los aspectos extra y post carcelarios. Finalmente, se presentaran algunas ideas a manera de conclusión.

\section{LA NORMATIVA INTERNACIONAL Y LAS RECOMENDACIONES, DIRECTRICES Y REGLAS ONU EN MATERIA PENITENCIARIA.}

Como es sabido, Novelli definió tempranamente el Derecho penitenciario como "el conjunto de normas jurídicas que regulan la ejecución de las penas y las medidas de seguridad, a comenzar desde el momento en que se convierte en ejecutivo el título que legitima la ejecución"16. Sin embargo, como bien señaló Cuello Calón en su momento, tal definición o calificación original de Derecho penitenciario surgió para designar exclusivamente a ciertas y determinadas penas, las privativas de libertad, y a sus diversos sistemas de ejecución, ambos claramente inspirados en un sentido de la pena propia o cercana a la expiación reformadora ${ }^{17}$. Adjetivo que, ya incluso en su tiempo, fue ampliamente criticado, no sólo por la carga religiosa que etimológicamente el concepto penitenciario arrastra, sino por ser incluso señalado como un lastre para su desarrollo como disciplina científica ${ }^{18}$.

${ }^{16}$ Novelli, Giovanni, L'autonomia del Diritto Penitenziario, en Rivista di Diritto Penitenziario (1933), p. 5; Novelli, Giovanni, La autonomía del Derecho penitenciario, en Revista Penal y Penitenciaria 29-30 (1943), p. 425.

${ }^{17}$ Cuello Calón, Eugenio, Derecho Penal. Parte General (T.1, 13a edición, Barcelona, Bosch, 1960), pp. 745-746.

${ }^{18}$ Así, Telléz Aguilera, Abel, Novelli y su tiempo. Una aproximación a los orígenes y al concepto de Derecho penitenciario, en Revista de Estudios Penitenciario 255 (2011), 
Hoy, en cambio, resulta evidente que tal contenido inicial del Derecho penitenciario ha dado lugar progresivamente a áreas o contenidos distintos y más amplios que la mera expiación. Ejemplo evidente de ello, es su extensión hacia el fin resocializador, hacia la aplicación o ejecución de medidas de seguridad, el establecimiento y supervigilancia de recintos post carcelarios de carácter asistencial o de la ejecución masiva de otro tipo de penas no necesariamente privativas de libertad o alternativas a ésta. Todo ello fruto, no sólo del propio desarrollo de los distintos sistemas carcelarios ${ }^{19}$, en países como Italia ${ }^{20}$, Francia ${ }^{21}$ o España $a^{22}$ o de la

p. 10. En el mismo sentido, Marcó del Pont, Luis, Derecho penitenciario (2a edición, México D.F., Cárdenas, México D.F., 1998), p. 9.

${ }^{19} \mathrm{Al}$ respecto, véase PAVARINI, Massimo, El orden carcelario. Apuntes para una historia material de la pena, en BAIGún, David - BINDER, Alberto - MAYER, Julio, El derecho penal hoy. Homenaje al profesor David Baigun (Buenos Aires, del Puerto, 1995), pp. 567-596; PaVArini, Massimo, Fuera de los muros de la cárcel: la dislocación de la obsesión correccional, en Bustos Ramírez, Juan (dir.), Prevención y teoría de la pena (Santiago, Ed. Jurídica Cono Sur, 1995), pp. 155-174; MarCó del Pont, cit. (n. 18), pp. 55-176. BaratTA, cit. (n. 10), pp. 193-208; BaratTA, Alessandro, Observaciones sobre las funciones de la cárcel en la producción de las relaciones sociales de desigualdad', en Baratta, Alessandro, Criminología y sistema penal. (compilación in memoria) (Buenos Aires, B de F, 2004), pp. 357-375; SÁncheZ, Cristóbal, La aparición y evolución de los sistemas penitenciarios", en Anales de Derecho 31 (2013), pp. 139-179; Mata y Martín, Ricardo, Fundamentos del sistema penitenciario (Madrid, Tecnos, 2016), pp. 117 y ss.

${ }^{20}$ Desde el s. XX, y la importante obra de Giovanni Novelli, veáse Telléz, cit. (n.18), pp.12-22. Para una historia del sistema carcelario italiano, véase Neppr MoDONA, Guido, Carcere e società civile, Storia d'Italia V (Torino, Documenti Einaudi, 1973), II, pp. 1903-1998; Neppi Modona, Guido, Appunti per una storia parlamentare della riforma penitenziaria, en La Questione Criminale 3 (1976), 2, pp.319-372; Zepri, Arianna, La riforma dell'ordinamento penitenziaro, en AmbienteDiritto. It Rivista Giuridica (2005); Troncone, Pasquale, Manuale di Diritto Penitenziario (Torino, Giappichelli, 2006), pp. 51-64; Della Ragione, Luca, Compendio de Esecuzione e Diritto Penitenziario (Bari, Molfetta, Nel Diritto, 2019), pp. 231-235.

${ }^{21}$ Sobre las distintas etapas de evolución de su sistema carcelario, véase DuroCHÉ, Jean-Philippe - PÉDron, Pierre, Droit Pénitentiaire (3a édition, Vuibert, Paris, 2016), pp. 17-56.

${ }^{22} \mathrm{Al}$ respecto, véase BuEno ARÚs, Francisco, Historia del Derecho penitenciario Español, en Bueno, Francisco - De La Cuesta, José, Lecciones de Derecho Penitenciario (2a edición, U. de Alcalá de Henares, Salamanca, 1989), pp. 9-30; Giménez-Salinas, Esther, Autonomía del Derecho penitenciario. Principios informadores en la LOGP, Derecho penitenciario. Cuadernos de Derecho Judicial 33 (Madrid, Consejo General del Poder Judicial, 1995), pp. 69 y ss., especialmente pp. 71-75; GarCíA, Carlos Figueroa, María, La Justicia penal y penitenciaria entre el Antiguo Régimen y el Moderno: los años de consolidación, en GARCía VALDÉs, Carlos et al., Estudios penales en homenaje a Enrique Gimbernat (Madrid, Edisofer, 2008), II, pp. 2327-2355. Sobre 
influencia directa sobre su contenido de las diversas corrientes o teorías de la pena que, a partir de comienzos del s. XX, le disputan a la retribución su exclusividad como teoría y praxis de la justificación de la pena. Sino también, de la creciente normativa internacional que, desde mediados del s. XX, ha venido a complementar el escaso contenido material del tradicional Derecho penitenciario, desde los Derechos fundamentales, a través de la Constitución.

Por ello, como bien se señala respecto del caso Italiano, aunque la ley penitenciaria fue originalmente conceptualizada sólo como un sector del derecho administrativo, que específicamente sólo reglaba la disciplina y organización de hombres y medios dentro de una institución carcelaria, los criterios organizativos de la vida en prisión no pueden ignorar los cánones que inspiran las actuales normas constitucionales en materia de ejecución de pena, puesto que los principios sustanciales y de fines de la pena que gobiernan esta materia han terminado por incidir finalmente en aquellas ${ }^{23}$.

Más aún, en relación a este último punto, debe considerarse que la generalidad de la normativa internacional, los acuerdos y tratados internacionales suscritos por múltiples Estados nacionales aplicables a la materia penitenciaria, son además de aplicación obligatoria -y directa- en virtud no sólo de las respectivas Constituciones sino de las nuevas normas incluidas en las más recientes reformas procesales penales, por tratarse precisamente de temas vinculados directamente con los Derechos Humanos. Baste para explicitar lo anterior, en el caso chileno, el mandato contenido en el art. 5 inc. $2^{\circ}$ de la Constitución Política de la República y las múltiples normas del Código Procesal Penal que hacen mención a la obligatoria aplicación directa de los Tratados Internacionales.

Es por ello que no nos debe extrañar que, dentro de sus múltiples tareas del período post segunda guerra mundial, haya sido precisamente la Organización de Naciones Unidas quien se haya preocupado de generar, aprobar y establecer el modelo jurídico minimo de Derecho penitenciario para aquellos países regidos por el Estado de Derecho, orientados hacia la pena resocializadora y el respeto de los derechos fundamentales de los condenados por la comisión de un delito.

Entre tal normativa internacional debe destacarse, entre otras, la propia Declaración Universal de $D^{D} H^{24}$; el Pacto Internacional de Derechos

el sistema penitenciario español actual, en detalle, Fernández, Luis - Nistal, Javier, Derecho Penitenciario (Pamplona, Aranzadi-Thomson Reuters, 2016), pp. 365 y ss.

${ }^{23}$ Así, Troncone, cit. (n. 20), p.15.

${ }^{24}$ Organización de Naciones Unidas, Asamblea General, Declaración Universal de los Derechos Humanos (Paris, Resolución 217 A III, 1948). 
Civiles y Politicos ${ }^{25}$ : Las Reglas minimas para el tratamiento de los reclusos ${ }^{26}$; los denominados Conjunto de principios para la protección de todas las personas sometidas a cualquier forma de detención o prisión ${ }^{27}$ : Los Principios básicos para el tratamiento de los reclusos, que contiene 11 principios que reiteran lo establecido en los demás instrumentos internacionales respecto a los derechos de los reclusos ${ }^{28}$; las Reglas minimas de las Naciones Unidas sobre las medidas no privativas de la libertad (Reglas de Tokio) ${ }^{29}$; Las Reglas minimas ONU para la administración de la justicia de menores (Reglas de Beijing $)^{30}$; Las Reglas de las Naciones Unidas para la protección de los menores privados de libertad ${ }^{31}$; las Estrategias y medidas prácticas modelo para la eliminación de la violencia contra los niños en el campo de la prevención del delito y la justicia pena ${ }^{22}$; La Convención contra la tortura y otros tratos o penas crueles, inhumanas o degradantes ${ }^{33}$; los Principios básicos sobre la utilización de programas de justicia restaurativa en materia pena ${ }^{4}$; las Reglas de las Naciones Unidas para el tratamiento de las reclusas y medidas no

${ }^{25}$ Organización de Naciones Unidas, Asamblea General, Pacto Internacional de Derechos Civiles y Políticos (New York, Resolución 2200 A (XXI), 1966).

${ }^{26}$ Organización de Naciones Unidas, Asamblea General, Consejo Económico y Social (New York, Resolución 663C (XXIV), 1957) y (New York, Resolución 2076 (LXII), 1977).

${ }^{27}$ Organización de Naciones Unidas, Asamblea General, Conjunto de principios para la protección de todas las personas sometidas a cualquier forma de detención o prisión (New York, Resolución 43/173, 1988).

${ }^{28}$ Organización de Naciones Unidas, Asamblea General, Principios básicos para el tratamiento de los reclusos (New York, Resolución 45/ 111, 1990).

${ }^{29}$ Organización de Naciones Unidas, Asamblea General, Reglas mínimas de las Naciones Unidas sobre las medidas no privativas de la libertad (Reglas de Tokio) (New York, Resolución 45/110, 1990).

${ }^{30}$ Organización de Naciones Unidas, Asamblea General, Reglas minimas ONU para la administración de la justicia de menores (Reglas de Beijing; Resolución 40/33, anexo, 40 U.N. GAOR Supp. (N 53), p. 207, ONU Doc. A/40 /53, 1985).

${ }^{31}$ Organización de Naciones Unidas, Asamblea General, Reglas de las Naciones Unidas para la protección de los menores privados de libertad (New York, Resolución 45/113, 1990).

${ }^{32}$ Organización de Naciones Unidas, Asamblea General, Estrategias y medidas prácticas modelo para la eliminación de la violencia contra los niños en el campo de la prevención del delito y la justicia penal (New York, Resolución 68/169, 2013).

${ }^{33}$ Organización de Naciones Unidas, Asamblea General, Convención contra la tortura y otros tratos o penas crueles, inhumanas o degradantes (New York, Resolución 39/46, 1984).

${ }^{34}$ Organización de Naciones Unidas, Consejo Económico y Social, Comisión de Prevención del Delito y Justicia Penal, Justicia Restaurativa (Viena, E/ CN.15/2002/5/Add.1, 2002). 
privativas de la libertad para las mujeres delincuentes (Reglas de Bangkok) ${ }^{35}$; y las Reglas Minimas de las Naciones Unidas para el Tratamiento de los Reclusos (Reglas Nelson Mandela) ${ }^{36}$. Todo lo anterior verificable, además, a través del Manual de instrucciones para la evaluación de la justicia penal de Naciones Unidas, medidas privativas y no privativas de libertad, el sistema penitenciario ${ }^{37}$. Más aún, el mantenimiento histórico de las cuestión penitenciaria y la persistencia de los Estados en ignorar tal situación, no obstante la existencia de esta contundente legislación internacional, ha llevado a la Organización de Naciones Unidas a atreverse a formular una serie de recomendaciones en materias tales como justicia restaurativa, con su Manual sobre Programas de Justicia restaurativa ${ }^{38}$; la aplicación de medidas sustitutivas, a través del Manual de principios básicos y prácticas prometedoras en la aplicación de medidas sustitutivas del encarcelamiento ${ }^{39}$, o respecto del hacinamiento penitenciario, con su Manual sobre estrategias para reducir el hacinamiento en las prisiones ${ }^{40}$.

Asimismo, en el ámbito específicamente americano, entre otros, se destacan; La Convención Americana sobre DDHH (Pacto San José de Costa Rica $)^{41}$; Los Principios y Buenas Prácticas sobre la Protección de las Personas Privadas de Libertad en las Américas ${ }^{42}$, y la Convención Interamericana para

${ }^{35}$ Organización de Naciones Unidas, Asamblea General, Reglas de las Naciones Unidas para el tratamiento de las reclusas y medidas no privativas de la libertad para las mujeres delincuentes (Reglas de Bangkok) (Viena, Resolución 65/229, $\Omega$ 2011).

${ }^{36}$ Organización de Naciones Unidas, Asamblea General, Oficina de las Naciones Unidas contra la droga y el delito, Reglas Minimas de las Naciones Unidas para el Tratamiento de los Reclusos (New York, Resolución 70/175, 2015).

${ }^{37}$ Organización de Naciones Unidas, Asamblea General, Oficina de las Naciones Unidas contra la droga y el delito, Manual de instrucciones para la evaluación de la justicia penal de Naciones Unidas, medidas privativas y no privativas de libertad, el sistema penitenciario (Viena, UNODC, 2010).

${ }^{38}$ Organización De Naciones Unidas, Asamblea General, Oficina de las Naciones Unidas contra la droga y el delito, Manual de programas de justicia restaurativa (Viena, UNODC, 2006).

${ }^{39}$ Organización de Naciones Unidas, Asamblea General, Oficina de las Naciones Unidas contra la droga y el delito, Manual de principios básicos y prácticas prometedoras en la aplicación de medidas sustitutivas del encarcelamiento (Viena, UNODC, 2010).

${ }^{40}$ Organización De Naciones Unidas, Asamblea General, Oficina de las Naciones Unidas contra la droga y el delito, Manual sobre estrategias para reducir el hacinamiento en las prisiones (Viena, UNODC, 2014).

${ }^{41}$ Organización De Estados Americanos, Convención americana sobre derechos humanos (San José, Conferencia especializada interamericana sobre Derechos $\mathrm{Hu}$ manos B-32, 1969).

${ }^{42}$ Organización De Estados Americanos, Comisión Interamericana de Dere- 
prevenir y sancionar la tortura ${ }^{43}$. Más aún, en las últimas décadas, el Instituto Latinoamericano de las Naciones Unidas para la Prevención del Delito y el Tratamiento del Delincuente (ILANUD), ha formulado diversas propuestas para el abordaje integral de la situación penitenciaria tanto en materia de adultos como en materia de jóvenes en conflicto con la ley ${ }^{44}$.

En el caso de la Unión Europea resulta más claro aún. Como bien señala Bueno Arús ${ }^{45}$, el Consejo de Europa ha pretendido desde antiguo, a través del Comité Europeo de Problemas Criminales y para el ámbito de sus Estados miembros, superar el modelo mínimo establecido a nivel internacional por la Organización de Naciones Unidas y, ya con fecha 19 de enero de 1973, el Comité de Ministros aprobó un Conjunto de reglas minimas para el tratamiento de los reclusos, modificadas y ampliadas por las actuales Reglas Penitenciarias Europeas, adoptada por el Comité de Ministros el 11 de enero de 2006. Reglas penitenciaria que, justamente, van más allá de las Reglas mínimas establecidas por Naciones Unidas en varios aspectos pues no sólo refuerzan el respeto de los Derechos Humanos de los reclusos y la vigencia del principio de legalidad de la ejecución, sino que adoptan nuevos métodos de tratamiento e incorporan modernos procedimientos resultantes del progreso tecnológico ${ }^{46}$.

De todo ello, surge claramente la constatación de la existencia de un imperativo normativo internacional, donde el creciente reconocimiento y respeto de los derechos fundamentales y la necesaria sistematización jurídica, han de contribuir a delimitar, aclarar y orientar no sólo el contenido del moderno Derecho penitenciario sino su reforma y perfeccionamiento. Sus nuevos fines, contenidos y materias, establecidos por las distintas constituciones y leyes penitenciarias comparadas, han de ayudar también

chos Humanos, Principios y Buenas Prácticas sobre la Protección de las Personas Privadas de Libertad en las Américas (Washington D.C., Resolución 1/08, OEA/Ser/L/V/ II.131 doc. 26, 2008).

${ }^{43}$ Organización De Estados Americanos, Asamblea General, Convención Interamericana para prevenir y sancionar la tortura (Cartagena de Indias, Tratado A-51, 1985).

${ }^{44} \mathrm{Al}$ respecto, en detalle, véase Carranza, Elias-houed, Mario-Et Al, Sistemas penitenciarios y alternativas a la prisión en América Latina y el Caribe (Buenos Aires, ILANUD-Depalma, 1992), especialmente, pp. 65 y ss.

${ }^{45}$ Así, Bueno Arus, Francisco, El consejo de Europa y el Derecho Penitenciario, en Díez Ripolles, José - Romeo Casabona, Carlos et al., La ciencia del derecho penal ante el nuevo siglo. Libro homenaje al profesor Doctor don José Cerezo Mir (Madrid, Tecnos, 2003), pp. 1049-1064, especialmente, p. 1049.

${ }^{46}$ Consejo de Europa, Comité de Ministros, Reglas Penitenciarias Europeas (Estrasburgo, Recomendación Rec (2006) 2, 2006). En detalle, véase Mata y MarTín, cit. (n. 19), pp. 223 y ss. 
a desbordar el tradicional objeto administrativo del viejo Derecho penitenciario pues éste ya no se reduce -materialmente- a la mera ejecución de las sanciones penales privativas de la libertad.

Así, en un primer nivel de delimitación, y basado en las recomendaciones, directrices y reglas internacionales propuestas por $\mathrm{ONU}^{47}$, toda reforma penitenciaria debiese considerar la siguiente normativa como punto de inicio:

i) En relación a la prevención del delito: las Directrices de las Naciones Unidas para la prevención de la delincuencia juvenil (Directrices de Riad), de 1990; las Directrices de las Naciones Unidas para la cooperación y la asistencia técnica en la esfera de la prevención de la delincuencia urbana, de 1995; Directrices de las Naciones Unidas para la prevención del delito, de 2002.

ii) Respecto del tratamiento de los reclusos: el Conjunto de principios para la protección de todas las personas sometidas a cualquier forma de detención o prisión, de 1988; Los Principios básicos para el tratamiento de los reclusos, de 1990 y las Reglas Minimas de las Naciones Unidas para el Tratamiento de los Reclusos (Reglas Nelson Mandela) de 2015.

iii) Sobre la aplicación y contenido de las alternativas a la pena privativa de libertad: las Reglas minimas de las Naciones Unidas sobre las medidas no privativas de la libertad (Reglas de Tokio), de 1990 y los Principios básicos sobre la utilización de programas de justicia restaurativa en materia penal, del año 2000.

iv) Respecto de los niños y niñas privados de libertad: las Reglas mínimas para la administración de la justicia de menores (Reglas de Beijing) de 1985; las Reglas de las Naciones Unidas para la protección de los menores privados de libertad, de 1990 y las Estrategias y medidas prácticas modelo para la eliminación de la violencia contra los niños en el campo de la prevención del delito y la justicia penal, de 2014.

v) En relación a la mujer delincuente privada de libertad: las Estrategias y medidas prácticas modelo actualizadas para la eliminación de la violencia contra la mujer en el campo de la prevención del delito y la justicia penal, de 2010 y las Reglas de las Naciones Unidas para el tratamiento de las reclusas y medidas no privativas de la libertad para las mujeres delincuentes (Reglas de Bangkok) de 2011.

vi) Respecto de las personas extranjeras privadas de libertad: el Acuerdo modelo sobre el traslado de reclusos extranjeros y recomendaciones sobre el tratamiento de reclusos extranjeros de 1985.

${ }^{47}$ Organización De Naciones Unidas, Asamblea General, Oficina de las Naciones Unidas contra la droga y el delito, Abordando la crisis penitenciaria a nivel global, Estrategia 2015-2017 (Viena. UNODC, 2015). 
vii) Por último, respecto al acceso a la justicia penal en general y la penitenciaria en particular: los Principios y directrices de las Naciones Unidas sobre el acceso a la asistencia jurídica en los sistemas de justicia penal, de 2012.

\section{SistematizaCión de LAS PRINCIPALES PROPUESTAS DE MEJORAS EN MATERIA PENITENCIARIA REALIZADAS POR COMISIONES ESPECIALES Y LA DOCTRINA ESPECIALIZADA.}

Múltiples y con distintas orientaciones ideológicas son las recomendaciones y propuestas de mejoras que, en materia penitenciaria, se han planteado en las últimas décadas tanto en nuestro país como en países de nuestro entorno cultural. Éstas han surgido no sólo de la doctrina especializada sino también de comisiones especiales formadas para tal efecto. Grupos, comités o comisiones que, a su vez, se integran no sólo por académicos o miembros de Organismos No Gubernamentales sino también por funcionarios, operadores del sistema, políticos directamente vinculados al tema penitenciario y, en algunos casos, hasta los propios -eufemísticamente llamados- usuarios del sistema. En torno a tales propuestas, y ante el horrible cúmulo de datos e información empírica contrastada, se han sembrado legítimas esperanzas y grandes desafíos de mejoras. De allí su legitimidad y posible viabilidad ${ }^{48}$.

Por ello, lo que se intenta a continuación no es más que una propuesta de sistematización de aquellas recomendaciones que se han considerado más relevantes y aplicables, más allá de su origen nacional, no sólo por la calidad y generalidad de los contenidos y medidas propuestas, sino por ofrecer soluciones o recomendaciones prácticas y ajustables a un conjunto de Estados que comparten, a lo menos, los mismos problemas arriba reseñados ${ }^{49}$.

Es en este contexto, y en atención a la amplitud, perspectiva u objetivo de las mismas, que se pueden distinguir, de entre su gran variedad, dos grandes clases de recomendaciones o propuestas; las de carácter general y aquellas más específicas. Las recomendaciones o propuestas de carácter general, apuntan al objetivo de modificar o mejorar el sistema de ejecución de penas en su conjunto. Esto es, desde una visión más cercana a la teoría de la pena, postulan crear o fortalecer un sistema alternativo a la pena privativa de libertad; propender legislativamente a la racionalización normativa del

\footnotetext{
${ }^{48}$ Así, GǗrRI, cit. (n. 2), pp. 553-559.

${ }^{49}$ Para un análisis de los problemas más comunes al interior de las cárceles latinoamericanas, desde una perspectiva menos teórica más práctica y concreta, véase DAMmER, Lucia - ZúNiga, Liza, La cárcel: problemas y desafíos para las américas (Santiago, OEA-FLACSO Chile, 2008), pp. 17 y ss.
} 
uso de la pena privativa de libertad, en el conjunto del sistema de control social formal, y la opción de la reinserción social al interior de los recintos carcelarios y en el ámbito post penitenciario ${ }^{50}$. Por su parte, las propuestas más específicas, tienen por objetivo central fortalecer, desde distintos ángulos, el sistema penitenciario. Incluyendo en ello, por cierto, el aumento de sus estándares o niveles de protección de garantías fundamentales de los ciudadanos condenados a penas privativas de libertad. Sea desde la perspectiva netamente institucional o fortaleciendo los propios derechos del individuo, tanto durante su estancia en el régimen penitenciario como en la etapa post penitenciaria.

Así, desde lo general, especialmente se ha recomendado el fortalecimiento y la ampliación de programas socioeducativos dirigidos a la reinserción social de los condenados que contemplen un conjunto de actividades terapéutico-asistenciales y programas intensivos de formación, educativos, laborales y de interacción social. Lo que supone contar no sólo con los espacios necesarios y la capacidad instalada (equipos, herramientas, materia prima, insumos, etc.) para la habilitación de talleres ocupacionales, con programas socioeducativos que vinculen a la industria con el sistema penitenciario. También, es importante fomentar, equipar o fortalecer las escuelas penitenciarias y la oferta de educación formal a nivel de educación superior, especialmente en carreras técnicas. Esto podría implementarse mediante el establecimiento de acuerdos de cooperación con las Universidades, especialmente de carácter público. Por último, se ha destacado el rol que es este tipo de recomendaciones le cabe a la formación educativa en línea (online, virtual o no presencial) como alternativa viable para muchos internos que puedan o deseen realizar estudios superiores mientras cumplen su condena ${ }^{51}$.

A su vez, al interior de las recomendaciones de carácter general, se pueden distinguir aquellas propuestas más bien estructurales, que guardan relación con transformaciones sustanciales o de fondo, de aquellas propuestas más propias de la gestión. Las primeras, dada su naturaleza y

${ }^{50} \mathrm{Al}$ respecto, véase Consejo Para La Reforma Penitenciaria, Recomendaciones para una nueva política penitenciaria (Santiago, Gobierno de Chile-FLACSO Chile-Ceja-Paz Ciudadana-U. de Chile, 2010), pp. 7 y ss; Interpeace, Programa de tratamiento penitenciario yo cambio. Centro penal de apanteos, Santa Ana, El salvador, Sistematización de la experiencia (Guatemala, Interpeace, 2014), pp. 3 y ss.; MorALES, Ana María - PANTOJA, Rodrigo et al., Una propuesta de modelo integral de reinserción social para infractores de ley (Santiago, Fundación Paz Ciudadana-Instituto de Asuntos Públicos U. de Chile, 2018), pp. 110 y ss.

${ }^{51}$ En este sentido, Andrade, Laura - Carrillo, Adilio, El sistema penitenciario salvadoreño y sus prisiones (San Salvador, Instituto Universitario de Opinión Pública, 2015), p. 161. 
envergadura, claramente son de largo plazo, pues sólo pueden ser impulsadas por cambios en la legislación respectiva ya que implican reformas en áreas como el sistema de ejecución de penas, la creación o modernización del órgano encargado del control de los recintos carcelarios (Gendarmería), la refundación o redefinición de la estructura carcelaria o de la política de reinserción post penitenciaria. Las segundas, vinculadas más bien a la reforma y modernización del Estado, podrían ser implementadas en el corto o mediano plazo, dado que no dependerían necesariamente de modificaciones normativas, sino que principalmente de voluntades políticas y coordinación entre organismos ${ }^{52}$.

Por ello, respecto del establecimiento de concretos mecanismos de coordinación interinstitucional, se ha propuesto la creación de instancias que vigilen la efectiva aplicación, monitoreen y controlen la praxis de los beneficios penitenciarios y el cumplimiento de las penas alternativas y sustitutivas a la prisión. Esto tendería a favorecer el tránsito de los privados de libertad en las distintas fases del régimen progresivo y una efectiva aplicación y control de la concesión de los beneficios penitenciarios, de medidas cautelares alternativas a la prisión y de penas sustitutivas de la prisión, con mecanismos de verificación rigurosos que faciliten la rehabilitación de la conducta criminal y que eviten la evasión de la justicia y fomenten la reinserción social y los derechos de las víctimas ${ }^{53}$.

En el mismo sentido, se ha propuesto establecer mecanismos eficientes de coordinación interinstitucional entre el órgano de administración penitenciaria y el Ministerio de Salud, de forma tal que se permita gestionar adecuadamente la atención médica de las personas privadas de libertad, con el fin de que dicha atención no se limite al tratamiento de padecimientos ya adquiridos, sino al desarrollo de programas de salud preventiva que abarque tanto las dimensiones físicas, como las mentales y sociales. Evitando además con ello la desnaturalización de los ya deteriorados recintos penitenciarios ${ }^{54}$. En este sentido, resulta indispensable retomar las normativas internacionales referentes a los Derechos Humanos de los privados de libertad que padecen enfermedades terminales, a fin de aplicar

${ }^{52} \mathrm{Al}$ respecto, en detalle, véase Bulnes, Felipe - Collarte, Constanza-Et Al, Sistema carcelario en Chile: propuestas para avanzar hacia una mayor efectividad y reinserción, en Temas de la Agenda Pública 93 (Santiago, Centro de Políticas Públicas, Pontificia Universidad Católica de Chile, 2017), p. 8 y ss.

${ }^{53}$ En detalle, ANdrade - Carrillo, cit. (n. 51), pp. 162-163.

${ }^{54} \mathrm{Al}$ respecto, Rodríguez YaGüe, Cristina, Cuando los centros penitenciarios se convierten en hospitales, psiquiátricos y asilos: aspectos regimentales y tratamentales de la gestión de la enfermedad y la ancianidad en prisión, en Revista General de Derecho Penal 32 (2019), pp. 1 y ss. 
los mecanismos legales que permitan la flexibilización de las condiciones de estas personas durante la ejecución de su condena. Esto incluye facilitar la salida de aquellos internos que estén en la fase terminal de su enfermedad, a fin de que puedan pasar sus últimos días bajo el cuidado de su familia y con mejores condiciones que las que ofrece el sistema penitenciario ${ }^{55}$.

Más aún, entre otras recomendaciones sanitarias específicas, se ha sugerido mejorar la infraestructura de salud de los penales para prevenir o erradicar las enfermedades infectocontagiosas, construir o habilitar pabellones de diagnóstico o atención psiquiátrica, establecer estrategias para la prevención y el control de enfermedades de transmisión sexual, degenerativas y congénitas ${ }^{56}$.

Igualmente, dentro de esta orientación general, se han planteado recomendaciones dirigidas a la necesidad de realizar estudios sobre la asignación presupuestaria de las respectivas instituciones encargadas de los recintos penitenciarios y de la distribución del gasto realizado al interior de los mismos. Ello, con el fin de permitir una formulación presupuestaria acorde a las prioridades y programas contemplados en la Política Penitenciaria y a las proyecciones anuales de crecimiento de la población privada de libertad. Esta medida, se afirma, permitiría una distribución más eficiente de los recursos financieros para el fortalecimiento de la infraestructura penitenciaria, la ampliación de la capacidad instalada de los centros penitenciarios, la mejora de las condiciones de habitabilidad y la contratación y capacitación del personal penitenciario y equipos técnicos criminológicos ${ }^{57}$.

Especialmente relevantes en este punto son las recomendaciones tendientes a dictar dispositivos normativos que, de acuerdo a su respectiva realidad carcelaria, vinculen a los Gobiernos Regionales y Locales con el sistema penitenciario con el fin de que realicen aportes presupuestarios y labores de apoyo en infraestructura, salud, educación y de funcionarios tendiente al tratamiento penitenciario y a la capacitación dentro de los

${ }^{55}$ En este sentido, ANdrade - Carrillo, cit. (n. 51), p.163. En Chile, respecto también del personal penitenciario, véase ZúNIGA, Liza, La cárcel enferma: consecuencias para reclusos y vigilantes (Serie documentos electrónicos 4, Programa seguridad ciudadana, FLACSO Chile, 2010), pp. 1 y ss.; respecto de la situación de los adultos mayores, véase MALDONADO, Francisco, Adulto mayor y cárcel: ¡cuestión humanitaria o cuestión de derechos?, en Politica Criminal 14 (2019), 27, pp. 1-46.

${ }^{56}$ Así, Ministerio de Justicia y Derecho Humanos, 10 medidas de reforma del sistema penitenciario (Lima, 2012), pp. 6-7.

${ }^{57}$ En este sentido, ANDrade - Carrillo, cit. (n. 51), p. 159. Sobre el gasto público en el sistema penitenciario chileno, véase CASTillo, Alejandra - ConTreras, José, Sistemas penitenciarios comparados, en Revista 935 (2011), pp. 11 y ss. 
penales dando oportunidad a los miembros de sus respectivas comunidades regionales o locales para que se reinserten y dejen la actividad delictiva ${ }^{58}$.

Por otra parte, se pueden individualizar iniciativas o propuestas más específicas y que tienen por objetivo central fortalecer, desde distintos ángulos, el sistema penitenciario. Entendiendo por ello, por cierto, aumentar sus estándares o niveles de protección de garantías fundamentales de los ciudadanos condenados a penas privativas de libertad. Sea desde la perspectiva netamente institucional o fortaleciendo los propios derechos del individuo, tanto durante su estancia en el régimen penitenciario como en la etapa post penitenciaria. Esto es, crear o fomentar sistemas de control externo, de carácter jurisdiccional, tanto para el momento de ejecución o cumplimiento de la pena privativa de libertad como respecto de la reinserción post penitenciaria. Lo que implica no sólo la protección de los derechos fundamentales de los condenados, sino también el resguardo de situaciones como la continuidad de intervenciones penales en adolescentes sancionados como tales pero que pasan a cumplir penas como adultos al cumplir la mayoría de edad ${ }^{59}$. Materias que, además, están directamente vinculadas a la decisión de creación, determinación de funciones y otorgamiento de competencias que se le concedan al Juez de Vigilancia Penitenciaria, al Tribunal de ejecución de penas o al Tribunal Penitenciario ${ }^{60}$.

Concretamente, en este sentido específico, se ha recomendado aumentar la asignación presupuestaria para mejorar la infraestructura física, la provisión de servicios básicos e incrementar el personal de los equipos técnicos, en aquellos centros penitenciarios que presentan los mayores niveles de población y albergan personas con mayores niveles de vulnerabilidad como las mujeres, adultos mayores y personas con trastornos psiquiátricos. De igual forma, se propone aumentar la capacidad instalada de las cárceles para reducir los elevados niveles de hacinamiento y contar con mejores condiciones físicas para desarrollar los programas de rehabilitación. Como también, implementar planes y estrategias de clasificación, separación y traslado de los internos con base a los criterios técnicos establecidos por ley, que permita un mejor control de los internos, garantizar su seguridad y

${ }^{58}$ En este sentido, Ministerio de Justicia y Derecho Humanos, cit. (n. 56), p. 8. En detalle, Organización de Naciones Unidas, Manual de instrucciones para la evaluación de la justicia penal, cit. (n. 38), pp. 35-36.

${ }^{59}$ Así, Consejo Para La Reforma Penitenciaria, cit. (n. 51), pp. 7 y ss.

${ }^{60} \mathrm{Al}$ respecto, véase Racionero, Francisco, El Juez de Vigilancia Penitenciaria: historia de un afán. minorías y prisión, en Eguzkilore 12 (1998), pp.37-59; MATTHEWs, Roger, cit. (n. 7), pp. 296-338, especialmente, pp. 304 y ss.; MORAles, Ana María Welsch, Gherman - Hurtado, María Teresa, Estudio comparado sobre tribunales de ejecución de Penas (Santiago, Fundación Paz Ciudadana, 2015). pp. 20 y ss. 
favorezca su evolución en el régimen progresivo. Para ello, se estima como fundamental aprobar y dar continuidad a una política de profesionalización del personal penitenciario, mediante el fortalecimiento y la cualificación de los programas de reclutamiento, formación y evaluación que debe desarrollar la respectiva institución a través de una Escuela Penitenciaria autónoma y acreditada académicamente ${ }^{61}$.

Asimismo, respecto de la clasificación, separación y traslado de internos, se ha indicado como una recomendación específica no sólo la de fomentar y perfeccionar los sistemas científicos que tengan por finalidad efectuar una correcta labor de clasificación penitenciaria, separando a los internos primarios de los reincidentes. Se buscará enfatizar el trabajo de diagnóstico y separación con adolescentes, jóvenes y primarios o primerizos, quienes habitualmente son las personas con mayor probabilidad de reinserción, reduciendo así la tasa de reincidentes o reingresos al sistema penitenciario $^{62}$. En este contexto, resultan relevantes, por su carácter de ejemplos de intentos de construcción de una política pública en materia penitenciaria, dos casos recientes, el de Uruguay y el de México.

En el caso Uruguayo, la propuesta surge a propósito de una visita del informador especial sobre tortura de Naciones Unidas, el destacado abogado y juez internacional Manfred Nowak, quien le hace presente una serie de recomendaciones vinculadas directamente con su sistema penitenciario y de justicia penal. Además de aquellas relacionadas con la materia propia de la visita, esto es, la lucha contra la impunidad y reparación para las víctimas de tortura.

Entre éstas ${ }^{63}$, destacan aquellas de carácter institucional, como la necesaria reforma del sistema de administración de justicia penal y penitenciaria centrada en un modelo encaminado a la prevención del delito y la resocialización de los delincuentes, en lugar de aquél orientado a las medidas punitivas y a la adopción de políticas basadas simplemente en encerrar a los sospechosos y a los delincuentes convictos. La creación de un Ministerio de Justicia que sea responsable del sistema penitenciario,

${ }^{61}$ En este sentido, en detalle, véase Andrade, Laura-Carrillo, Adilio, cit. (n. 51), pp. 156-161; Bulnes - Collarte et al., cit. (n. 53), pp. 10-12.

${ }^{62}$ En este sentido, véase Ministerio De Justicia y Derecho Humanos, cit. (n. 56), p. 8; Organización de Naciones Unidas, Manual de instrucciones para la evaluación de la justicia penal, cit. (n. 37), pp. 9-10. Bulnes - Collarte, cit. (n. 52), pp. 12-13.

${ }^{63}$ En detalle, véase Organización De Naciones Unidas, Asamblea General, Consejo de Derechos Humanos, Informe del Relator Especial sobre la Tortura y otros tratos o penas crueles, inhumanos o degradantes. Manfred Nowack. Misión al Uruguay (A/HRC/13/39/Add.2, New York, 2009), pp.23-25. 
dentro del marco de una reforma global del sistema de justicia penal. Dentro de este nuevo ministerio, crear un cuerpo de guardias de prisiones bien entrenado y dotado de recursos que sustituya a los oficiales de policía que desempeñan esa función ya que la escasez de personal en los centros de reclusión conduce a una falta de seguridad para los propios miembros de ese personal y les dificulta el cumplimiento de su obligación de proteger a los internos de la violencia entre los reclusos.

También deben relevarse aquellas recomendaciones vinculadas al uso de la reclusión y a las condiciones en el cumplimiento de penas, tales como, la que recomienda la limitación del uso de la prisión preventiva, el mejoramiento de las condiciones de reclusión a través, entre otras, del establecimiento de normas mínimas de habilitabilidad y acceso al trabajo y a la educación, la clausura del uso de módulos de chapa metálica o de latas en determinados Penales, separar procesados de condenados, garantizar exámenes médicos en ocasión de ingresos, traslados y egresos, y en general extender la atención de salud a los reclusos. Esto es, asegurar que las personas privadas de libertad estén recluidas en centros penitenciarios en condiciones que cumplan las normas mínimas sanitarias e higiénicas internacionales y que los internos vean satisfechas sus necesidades básicas, como espacio suficiente, ropa de cama, alimentos y cuidado de la salud. Facilitar a los internos posibilidades de trabajar y estudiar, así como de realizar actividades de ocio y rehabilitación. Así como el deber de abordar de inmediato el problema crónico del hacinamiento. Y, por último, son destacables aquellas que guardan relación con la modificación del sistema de administración de justicia penal para los menores infractores, que debiera encaminarse hacia un sistema de justicia moderno que tenga por objetivo la prevención y la rehabilitación del menor infractor, y la introducción de programas de atención al consumo problemático de sustancias en los centros de privación de libertad para éstos.

Sobre esta base de recomendaciones, en el Uruguay se han presentado una serie de propuestas orientadas a contribuir a la consolidación de tales recomendaciones, indispensables para la estructuración de una política pública realista y seria sobre el sistema de justicia penal y penitenciaria, partiendo de la valoración y el reconocimiento a lo conseguido en los últimos años pero identificando los temas pendientes, los vacíos y los principales obstáculos. Con esta lógica, fundamentos y objetivos, destacados investigadores han realizado sus propias propuestas y recomendaciones, a través del Servicio Paz y Justicia del Uruguay, como una base metodológica fundamental para la construcción y ejecución de una reforma en estas materias, aquella que tiene por objeto el diseño, la ejecución y la evaluación 
de una política pública penitenciaria a partir de una amplia consulta a los diversos actores implicados en el sistema ${ }^{64}$.

Según tal propuesta, la formulación de tal política pública debe tener un claro y sólido plan estratégico, elaborado a través de las siguientes etapas: Establecimiento de la agenda, cuya prioridad debe ser la reforma integral del sistema penitenciario. La definición de los problemas, que debe diferenciar la identificación de los mismos respecto de su conocimiento técnico. A tal efecto, el análisis de sus componentes, así como sus probables causas y los efectos derivados de ellos, deben ser abordados desde una sólida perspectiva técnica puesto que, las experiencias comparadas estudiadas en la propuesta, muestran que muchos de los fracasos de las políticas públicas en la materia se deben al hecho de no haber definido correctamente los problemas en el inicio del plan. La Previsión del plan y su realización con vocación de futuro. Las propuestas de la política pública penitenciaria deben trascender el gobierno de turno y, más allá de intentar dar respuesta a una cuestión de actualidad, debe prever su mejoramiento a futuro así como tener capacidad de prever realidades que aún no se presentan pero que pueden hacerlo a futuro. Clara determinación de las metas, tanto actuales como a futuro. Esto implica establecer las características genéricas del sistema penitenciario deseado luego de la reforma integral. Se trata de una etapa compleja pues es necesario evaluar profunda y críticamente cada una de las propuestas impulsadas: su coherencia, su complementariedad, su adecuación a la realidad actual y al futuro esperado, donde las experiencias comparadas son una rica fuente inspiradora. Selección de la opción, etapa que deviene de la clara definición de las metas y objetivos de la política pública. Implica procedimientos de decisión en el marco de un catálogo de opciones, tales como; ser o no un servicio público penitenciario, nacional o autónomo; que comprende, o no, la ejecución de las medidas restrictivas de la libertad ambulatoria así como las medidas sustitutivas o alternativas a la privación de libertad; que garantiza los derechos humanos; que se orienta por determinados principios, como integralidad, coordinación con las políticas públicas sociales, progresividad, transversalidad y promoción de la responsabilidad social a través del trabajo o la capacitación educativa, etc. ${ }^{65}$.

En el mismo sentido metodológico, pero más relacionado a la vinculación que debe existir entre los valores declarados en los instrumentos y tratados internacionales, la generación de normas internas y las políticas públicas reformistas, la propuesta en comento aboga por el necesario

${ }^{64}$ Véase Juanche, Ana - Palummo, Javier (coords.), Hacia una política de Estado en privación de libertad. Diálogo, recomendaciones y propuestas (Montevideo, SERPAJ Uruguay-Observatorio del Sistema Judicial, 2012).

${ }^{65}$ En detalle, Juanche - Palummo, cit. (n. 64), pp. 281-286. 
reenfoque coherente la política criminal en materia penitenciaria. Esto, a propósito de la existencia o la generación de normas que, más allá de la legítima autoridad y potestad legislativa del Estado, denotan o dejan de manifiesto situaciones de total falta de coherencia de la política criminal. Es decir, casos donde al mismo tiempo que se impulsan acciones concretas para el mejoramiento del sistema carcelario, el propio Estado también impulsa otras modificaciones claramente de carácter regresivo, propias del populismo punitivo, que promueven la mera expansión del Derecho penal y procesal penal o que flexibilizan el sistema de garantías sustanciales y procesales. Esta falta de coherencia, lejos de contribuir a la humanizar el sistema, genera incertidumbre y deslegitima el proceso de reforma, contradiciendo los estándares establecidos por los instrumentos normativos suscritos, pero sobre todo perpetuando las condiciones de vida y trato inhumano de las personas privadas de libertad ${ }^{66}$.

Por último, respecto de la praxis y objetivos del sistema de ejecución de penas y su vinculación con los aspectos institucionales, se debe destacar la idea contenida en estas recomendaciones en torno a que el combate al hacinamiento carcelario es el primer paso de la reforma del sistema penitenciario, lo que requiere promover cambios multidimensionales profundos y sostenibles en el tiempo, donde la ejecución de la pena debe estar orientada a la preparación de la persona para su reincorporación a la vida en libertad, bajo el más estricto cumplimiento a la integralidad de los derechos humanos ${ }^{67}$. Entre estos cambios, se postula la creación de una Ley de Ejecución de Penas que comprenda además normas sobre el funcionamiento de un Instituto Nacional de Rehabilitación ${ }^{68}$. Se recomienda el diseño, la articulación y la ejecución de programas y dispositivos de apoyo y seguimiento al proceso de egreso y reinserción social ${ }^{69}$. Todo ello, junto a la modificación de la estructura institucional penitenciaria con el objetivo de estructurar un sistema nacional cuyo objeto sea estimular de manera individualizada la educación y la aptitud para el trabajo de las personas condenadas por infracciones a la ley penal ${ }^{70}$. Lo que implica, a su vez, no sólo dotar al sistema de personal técnico-profesional con carácter civil, capacitado para la tarea y comprometido con tales funciones, ${ }^{71}$ sino también

${ }^{66}$ En este sentido, véase JuAnChe - Palummo, cit. (n. 64), pp. 286-288.

${ }^{67}$ En detalle, véase JuAnche - Palummo, cit. (n. 64), pp. 291-293.

${ }^{68}$ En detalle, véase Juanche - Palummo, cit. (n. 64), pp. 289-291.

${ }^{69}$ En detalle, véase Juanche - Palummo, cit. (n. 64), pp. 293-294.

${ }^{70}$ Sobre sus características, objetivos, organización del sistema penitenciario propuesto y sobre la estructura interna de los recintos, véase JUANCHE - PALUmMO, cit. (n. 64), pp. 295-303.

${ }^{71}$ En detalle, véase JuAnCHe - Palummo, cit. (n. 64), pp. 304-305. 
fortalecer y ampliar la cobertura y el alcance del sistema de seguimiento de las medidas alternativas a la privación de libertad y la libertad asistida ${ }^{72}$.

México, por otra parte, nos presenta otra idea específica de propuestas de mejoras de la política pública penitenciaria, en un contexto de mayor especificidad, a través de una obra colectiva presentada por el Centro de Análisis de Políticas Públicas de México ${ }^{73}$.

Dichas propuestas parten de la constatación empírica de ciertos datos y realidades que, como arriba ya hemos señalado, lamentablemente resultan reiterativos en nuestro entorno cultural, tales como, principalmente, el uso excesivo de la prisión como medida cautelar y como sanción en todo México. Como también, el hecho que las condiciones de la prisión están lejos de ser las óptimas, por lo que no cumple con su objetivo formal, que es reinsertar a los internos a la sociedad, tal como dicta expresamente el artículo 18 de la Constitución Política de los Estados Unidos Mexicanos ${ }^{74}$.

Lo interesante es que tales propuestas parten de una visión contraria a dos ideas generalmente centrales a la hora de plantear una política pública en el área penitenciaria: la lucha contra el hacinamiento carcelario a través de la construcción de nuevos recintos y la creación de nuevos tipos penales con penas de corta duración.

Respecto de lo primero, se argumenta que ello no es sustentable, al menos por tres razones. Por su temporalidad como solución, pues si continúan los mismos patrones delictivos y los mismos procesos judiciales, en algunos años la ocupación llegará al límite nuevamente. En segundo lugar, porque la cárcel representa costos directos muy altos, los cuales incluyen la construcción y administración de los penales, así como la manutención de los internos. Y porque la prisión trae consigo costos indirectos importantes, como las consecuencias negativas que estas penas tienen para los familiares de los internos y para la comunidad en general. Por tales motivos, se afirma, es imprescindible buscar alternativas a la prisión. Respecto de los segundo, se sostiene que las condenas cortas tienen efectos criminógenos sobre los sentenciados, por lo cual se debería hacer de las penas privativas

${ }^{72}$ En detalle, véase JuAnche - Palummo, cit. (n. 64), pp.305-306.

${ }^{73}$ Véase Solís, Leslie - De Buen, Néstor - Ley, Sandra, La cárcel en México ¿para qué? (México D.F., México Evalúa, Centro de Análisis de Políticas Públicas A.C., 2013).

${ }^{74} \mathrm{La}$ Constitución Política de los Estados Unidos Mexicanos, en su inc. $2^{\circ}$ del Art. 18, prescribe; "El sistema penitenciario se organizará sobre la base del respeto a los derechos humanos, del trabajo, la capacitación para el mismo, la educación, la salud y el deporte como medios para lograr la reinserción del sentenciado a la sociedad y procurar que no vuelva a delinquir, observando los beneficios que para él prevé la ley. Las mujeres compurgarán sus penas en lugares separados de los destinados a los hombres para tal efecto". 
de libertad la última respuesta de la sociedad, sobre todo para delitos menores no violentos. Por lo anterior, se afirma, se hace necesario considerar seriamente reformas al sistema penitenciario que permitan modificar las actuales tendencias de crecimiento de la población carcelaria y así controlar también las consecuencias asociadas ${ }^{75}$.

Dentro de las propuestas o recomendaciones generales de política pública para transformar el uso actual de la cárcel en México, puede destacarse la idea de realizar una profunda revisión de la legislación penal para eliminar la sanción carcelaria para algunos delitos. En este sentido, se plantea la idea de que muchas de las conductas que actualmente suelen estar configuradas como delitos, podrían salir de los códigos penales y recibir un tratamiento mediante infracciones y otras sanciones no privativas de la libertad. Como ejemplo, se señalan los accidentes de tránsito que arrojen sólo daños materiales y no presenten una conducción culpable por parte de los conductores, las amenazas, riñas, los daños a la propiedad, entre otros, deben sancionarse a través del nuevo sistema denominado de justicia cívica ${ }^{76}$, o a través de mecanismos alternativos de resolución de controversias $^{77}$.

Consecuentemente con lo anterior, la propuesta recomienda desarrollar normativa e institucionalmente las sanciones no privativas de libertad, tales como los servicios comunitarios, multas y las figuras procesales como el tratamiento en libertad y la suspensión del procedimiento a prueba, entre otras de las establecidas en las Reglas minimas de las Naciones Unidas sobre las medidas no privativas de la libertad (Reglas de Tokio) de $1990^{78}$. Cambios que deben estar acompañados de presupuesto y personal para la atención de los usuarios y del seguimiento del cumplimiento de las prestaciones comprometidas, los pagos, el cumplimiento de las condiciones y de los tratamientos. Para ello, se propone la idea de desarrollar fideicomisos para que los recursos de las multas se apliquen a la reparación del daño de las víctimas en los casos en los que no se hayan esclarecido los hechos y no se hayan deslindado responsabilidades, así como para sostener los servicios

${ }^{75}$ En este sentido, Solís-De Buen - Ley, cit. (n. 73), p. 54.

${ }^{76} \mathrm{Al}$ respecto, véase el Decreto del 05 de febrero de 2017 por el que se declaran reformadas y adicionadas diversas disposiciones de la Constitución Política de los Estados Unidos Mexicanos, en materia de Mecanismos Alternativos de Solución de Controversias, Mejora Regulatoria, Justicia Cívica e Itinerante y Registros Civiles; Asimismo, véase Comisión Nacional De Seguridad, Secretaria de Gobernación, Sistema Nacional de Seguridad Pública, Modelo Homologado de Justicia Cívica, Buen Gobierno y Cultura de la Legalidad para los Municipios de México (México D.F., 2018).

${ }^{77}$ En este sentido, Solís - De Buen - Ley, cit. (n. 73), p. 54.

${ }^{78}$ Véase, Organización de Naciones Unidas, Reglas mínimas sobre las medidas no privativas de la libertad, cit. (n. 29). 
públicos de seguimiento. La idea fundamental es que los servicios a la comunidad, las multas, la colocación de localizadores electrónicos y las suspensiones de licencias no dejan de ser sanciones pero su legitimidad ante una sociedad atemorizada por la criminalidad depende de un seguimiento adecuado y eficaz ${ }^{79}$.

En el mismo sentido, las propuestas hacen mención al uso prudente de la prisión preventiva, a la revisión de la infraestructura con la que cuenta el Sistema Penitenciario Nacional, a la profesionalización del personal administrativo, técnico y de custodia, y a los eventuales beneficios que la implementación del nuevo sistema de justicia penal acusatorio, como mecanismo de utilización más racional de sanciones penales, pueda tener para el sistema penitenciario ${ }^{80}$.

Sin perjuicio de ello, resulta digna de relevar, por su carácter valorativo y teleológico, la propuesta relativa a la mejora e institucionalización de los programas y las técnicas de reinserción. Para ello, afirma la propuesta, resulta importante sistematizar las actividades en los diversos ámbitos de la salud, el deporte, la educación y el trabajo en torno a un tratamiento progresivo. Además, se señala la necesidad que un programa integral de reinserción deba incorporar un marco conceptual. Para esto, se deben determinar y homologar definiciones, contenidos y alcances de las actividades educativas, deportivas, de salud, laborales y de capacitación. Asimismo, una vez que el interno sale de la cárcel, se debe continuar con la evaluación del proceso de reinserción mediante un sistema de seguimiento post-penitenciario. Es decir, se debe verificar que los individuos que salen de prisión no infrinjan la ley de nuevo, cuenten con un trabajo legal, eviten tener contacto con grupos criminales, tengan una buena relación con sus familiares y seres queridos, se mantengan alejados de sustancias prohibidas, entre otras cosas. Por último, si se busca un sistema más completo, éste podría incluir la atención psicológica de quienes se reinsertan en la sociedad ${ }^{81}$.

\section{A MODO DE CONCLUSIÓN}

Desde distintas perspectivas, y con el aval de datos fácticos ampliamente contrastados, la profunda crisis del sistema penitenciario pone nuevamente de manifiesto la necesidad y relevancia de su reforma.

Para ello, no sólo debe considerarse la contundencia del imperativo normativo internacional, el creciente reconocimiento y respeto de los

\footnotetext{
${ }^{79}$ En detalle, véase Solís - De Buen - Ley, cit. (n.73), pp.54-55.

${ }^{80}$ En detalle, véase Solís - De Buen - Ley, cit. (n. 73), pp. 57-60.

${ }^{81}$ Así, Solís - De Buen - Ley, cit. (n. 73), p. 56.
} 
derechos fundamentales sino también la grave y permanente crisis del fin retributivo de la pena.

Asimismo, en esta tarea debe considerarse la relevante incorporación que, de fines preventivos y resocializadores respecto de la pena, han realizado distintas Constituciones. Todo ello, unido, a su vez, a los nuevos fines, contenidos y materias, establecidos consecuentemente por las distintas leyes penitenciarias comparadas.

De igual forma, para esta tarea reformadora, debe considerarse la necesidad de producir un punto de inflexión en materia penitenciaria a través del necesario reconocimiento del Derecho penitenciario como una disciplina jurídica autónoma, cuestión que se produce sólo desde el momento en que el respectivo sistema jurídico reconozca determinados derechos y garantías materiales y procesales al condenado durante la ejecución penal.

Más aún, el trabajo de reforma del sistema penitenciario debe considerar, además de la normativa internacional y de las recomendaciones, directrices y reglas de Naciones Unidas en materia penitenciaria, aquellas propuestas de mejoras realizadas por comisiones especiales y por la doctrina especializada en materia penitenciaria, especialmente respecto de los aspectos normativos e institucionales de la política pública penitenciaria, como también en cuanto a sus fines teleológicos, intra, extra y post carcelarios.

En este sentido, y en atención al objetivo de las mismas, se pueden distinguir dos grandes clases de recomendaciones o propuestas; aquellas de carácter general, que apuntan a la modificar el sistema de ejecución de penas en su conjunto; y aquellas más específicas, cuyo objetivo central es fortalecer, desde distintos ángulos, el sistema penitenciario. Ambas, sin embrago, pueden constituir una robusta política pública penitenciaria con elementos de carácter normativo, institucionales, procedimentales y valorativos.

\section{BiBLIOGRAFÍA}

AlCaíno, Eduardo, Derechos Humanos de los privados de libertad: las cárceles en chile: ¿avances o mantenimiento del status quo?, en Informe Anual de Derechos Humanos Chile (Santiago, UDP, 2018).

Altegrity Security Consulting, Sistema penitenciario chileno: el momento del cambio es ahora. Informe Final (Santiago, 2011).

Álvarez, Andrés - Domínguez, Andrés (eds.), El sol en la ciudad: Estudios sobre prevención del delito y modernización penitenciaria (Santiago, Comisión Chilena de DDHH, 1993).

ANDRADE, Laura CARRILlo, Adilio, El sistema penitenciario salvadoreño y sus prisiones (San Salvador, Instituto Universitario de Opinión Pública, 2015).

Arenas, Lorena - Cerezo, Ana, Realidad penitenciaria en Colombia: la necesidad de una nueva politica criminal, en Revista Criminalidad 58 (2016), 2. 
Arriagada, Isabel - Rochow, Diego, Privación de libertad en Chile: Desgobierno carcelario y afectación de derechos de la población penal en, UNIVERSIDAD DIEGO PorTales, Informe Anual de Derechos Humanos Chile (Santiago, UDP, 2015).

Arribas López, Eugenio, Aproximación a un 'Derecho penitenciario del enemigo', en Revista de Estudios Penitenciarios 253 (2007).

Baiguera Altieri, Andrea, Verso un nuovo Diritto Penitenziario, en Dirito.it (2019).

Baratta, Alessandro, Criminología critica y critica del Derecho penal. Introducción a la sociología jurídico penal (Buenos Aires, Siglo XXI, 2004).

Baratta, Alessandro, Observaciones sobre las funciones de la cárcel en la producción de las relaciones sociales de desigualdad, en BARATTA, Alessandro, Criminología y sistema penal (compilación in memoria) (Buenos Aires, B de F, 2004).

Binder, Alberto, Introducción al Derecho penal (Buenos Aires, Ad-Hoc, 2004).

Bueno Arus, Francisco, El consejo de Europa y el Derecho Penitenciario, en Díez RIpolles, José - Romeo CaSABOna, Carlos, La ciencia del derecho penal ante el nuevo siglo. Libro homenaje al profesor Doctor don José Cerezo Mir (Madrid, Tecnos, 2003).

Bueno Arús, Francisco, Historia del Derecho penitenciario Español, en Bueno, Francisco-De La Cuesta, José, Lecciones de Derecho Penitenciario (2a edición, Salamanca, U. de Alcalá de Henares, 1989).

Bulnes, Felipe - Collarte, Constanza, Sistema carcelario en Chile: propuestas para avanzar hacia una mayor efectividad y reinserción, en Temas de la Agenda Pública 93 (Santiago, Centro de Políticas Públicas, Pontificia Universidad Católica de Chile, 2017).

Bustos, Juan - Bergalli, Roberto - Miralles, Teresa, El pensamiento criminológico I. Un análisis crítico (Bogotá, Temis, 1983).

Cambronero Torres, Melissa, Derecho Penitenciario del enemigo: hacia un análisis politico-criminal del sistema penitenciario Costarricense (San Juan, Universidad de Costa Rica, , Tesis de licenciado en Derecho 2014).

Carnevali, Raúl - Maldonado, Francisco, El tratamiento penitenciario en Chile: especial atención a problemas de constitucionalidad, en Ius et Praxis 19 (2013), 2.

CARRANZA, Elias - HOUED, Mario, Sistemas penitenciarios y alternativas a la prisión en América Latina y el Caribe, (Buenos Aires, ILANUD-Depalma, 1992).

Castillo, Alejandra - Contreras, José, Sistemas penitenciarios comparados, en Revista 935 (2011).

Castro, Álvaro, Sistema Penitenciario y Derechos Humanos, en Universidad Diego PorTales, Informe Anual de Derechos Humanos Chile (Santiago, UDP, 2011).

Castro, Álvaro - Cillero, Miguel - Mera, Jorge, Derechos fundamentales de los privados de libertad. Guía práctica con los estándares internacionales en la materia (Santiago, UDP, 2010).

Cuello Calón, Eugenio, Derecho Penal. Parte General (13a edición, Barcelona, Bosch, 1960), I.

Dammer, Lucia - ZÚNiga, Liza, La cárcel: problemas y desafíos para las américas (Santiago, OEA-FLACSO Chile, 2008). DAmmert, Lucia - DíAz, Javiera, Cárceles privadas ¿modelo de gestión penitenciarias o inversión inmobiliaria?, en Observatorio 5 (2005).

Dammert, Lucia - Díaz, Javiera, Los desafíos del sistema carcelario en Chile (Caracas, CLACSO, 2004).

Dammert, Lucia - ZUÑIGA, Liza, La cárcel: problemas y desafíos para las américas (Santiago, FLACSO, 2008). 
Della Bella, Angela, Riforma dell'ordinamento penitenziario: le novità in materia di assistenza sanitaria, vita detentiva e lavoro penitenziario. Decreti legislativi 2 ottobre 2018, n. 123 e 124, en Diritto Penale Contemporaneo (2018).

Della Ragione, Luca, Compendio de Esecuzione e Diritto Penitenziario (Bari, Nel Diritto, Molfetta, 2019).

Dolcini, Emilio, La «nueva» reincidencia. La cárcel en Italia se vuelve todavía más selectiva, en GARCíA VALDÉs, Carlos (ed.), Estudios penales en homenaje a Enrique Gimbernat (Madrid, Edisofer, 2008), I.

DuCE, Mauricio - RIEGO, Cristián, La prisión preventiva en Chile: análisis de los cambios legales y su impacto (Santiago, Ediciones UDP, 2011).

Duce, Mauricio - Riego, Cristián, Prisión preventiva y reforma procesal penal en América Latina. Evaluación y perspectivas (Santiago, CEJA-JSCA, 2015).

Duroché, Jean-Philippe - Pédron, Pierre, Droit Pénitentiaire (3a édition, Vuibert, Paris, 2016).

Fernández, Luis - Nistal, Javier, Derecho Penitenciario (Pamplona, AranzadiThomson Reuters, 2016).

Foucault, Michel, Vigilar y castigar. Nacimiento de la prisión (1 $11^{\text {a }}$ edición, Madrid, Siglo XXI, 1998).

Gallego Díaz, Manuel, La desnaturalización del Derecho penitenciario por el Derecho penal: análisis de tres supuestos paradigmáticos en relación con el sistema de individualización cientifica, en ADPCP. 69 (2016).

García, Carlos-Figueroa, María, La Justicia penal y penitenciaria entre el Antiguo Régimen y el Moderno: los años de consolidación, en GarCía Valdés, Carlos- Et Al, Estudios penales en homenaje a Enrique Gimbernat (Madrid, Edisofer, 2008), II.

Gimbernat Díaz, Eva, El Derecho penitenciario del enemigo aplicable a los presos por delitos de terrorismo, en Cuerda Riezu, Antonio, El Derecho penal ante el fin de ETA (Madrid, Tecnos, 2016).

Giménez-Salinas, Esther, Autonomía del Derecho penitenciario. Principios informadores en la LOGP, Derecho penitenciario. Cuadernos de Derecho Judicial 33 (Madrid, Consejo General del Poder Judicial, 1995).

González Sánchez, Ignacio, Aumento de presos y Código Penal: una explicación insuficiente, en Revista Electrónica de Ciencia Penal y Criminología 13 (2011), 4.

GÜERRI, Cristina, La reforma penitenciaria será con los funcionarios o no será. Acerca de la necesidad de contar con el personal para lograr el cambio en la institución penitenciaria, en Papers 104 (2019), 3.

Guzmán, José Luis, Consideraciones críticas sobre el Reglamento Penitenciario chileno, en Gaceta Jurídica 168 (1994).

Juanche, Ana - Palummo, Javier (coords.), Hacia una política de Estado en privación de libertad. Diálogo, recomendaciones y propuestas (Montevideo, SERPAJ UruguayObservatorio del Sistema Judicial, 2012).

Kendall, Stephen, Tutela judicial efectiva en la relación jurídica penitenciaria (Santiago, Librotecnia, 2010).

Magan Zeballos, Julio, La sobrepoblación en el sistema penitenciario peruano, en International Review of the Red Cross 903 (2017).

Maldonado, Francisco, Adulto mayor y cárcel: ¿cuestión humanitaria o cuestión de derechos?", en Politica Criminal 14 (2019), 27.

MALDONADO, Mónica, Informe sobre los diversos problemas que afectan al funcionamiento del sistema carcelario en nuestro pais (2009). 
Mañalich, Juan Pablo, El derecho penitenciario entre la ciudadania y los derechos humanos, en Derecho y humanidades 18 (2011).

Mapelli Caffarena, Borja, Capitulo 1. Concepto y ámbito del Derecho penitenciario, en Mapelli, Borja - CaAmaño, Cristina - Espinoza, Olga, Ejecución de la pena privativa de libertad: una mirada comparada, Colección Documento de Trabajo 17 (Santiago, EUROsociAL, 2014).

Marcó del Pont, Luis, Derecho penitenciario (2a edición, México D.F., Cárdenas, 1998).

Mata y Martín, Ricardo, Fundamentos del sistema penitenciario (Madrid, Tecnos, 2016).

Mathiesen, Thomas, Juicio a la prisión. Una evaluación crítica (Buenos Aires, Ediar, 2003).

MATTHEWs, Roger, Una propuesta realista de reforma para las prisiones de Lationamérica en, Política criminal 6 (2011), 12. Melossi, Dario - PAVArini, Massimo, Cárcely fábrica. Los origenes del sistema penitenciario. Siglos XVI-XIX (Madrid, Siglo XXI, 1980).

Morales, Ana María - Pantoja, Rodrigo, Una propuesta de modelo integral de reinserción social para infractores de ley, (Santiago, Fundación Paz Ciudadana-Instituto de Asuntos Públicos U. de Chile, 2018).

Morales, Ana María - Welsch, Gherman - Hurtado, María Teresa, Estudio comparado sobre tribunales de ejecución de Penas (Santiago, Fundación Paz Ciudadana, 2015).

Murillo Rodríguez, Roy, Modernas tendencias en el Derecho penitenciario. Las propuestas del "Derecho penitenciario minimo", el "Derecho penitenciario del enemigo" $y$ las reformas del 2003 en el ordenamiento jurídico-penitenciario español (Getafe, Universidad Carlos III, Tesis Doctoral, 2009).

Neppi Modona, Guido, Appunti per una storia parlamentare della riforma penitenziaria, en La Questione Criminale 3 (1976), 2.

Neppi Modona, Guido, Carcere e società civile, Storia d'Italia (Torino, Documenti Einaudi, 1973), II.

Noel Rodríguez, María, Hacinamiento penitenciario en América Latina: causas y estrategias para su reducción (México D.F., Comisión Nacional de los Derechos Humanos de México, 2015).

Novelli, Giovanni, L'autonomia del Diritto Penitenziario, en Rivista di Diritto Penitenziario (1933).

Novelli, Giovanni, La autonomía del Derecho penitenciario, en Revista Penal y Penitenciaria 29-30 (1943).

Paccagnella Casari, Giorgia. La riforma dell'Ordinamento Penitenziario: soluzioni timide per problemi gravi, en Giurisprudenza Penale Web 3 (2019).

PAVARINI, Massimo, El orden carcelario. Apuntes para una historia material de la pena, en Baigún, David - Binder, Alberto - Mayer, Julio, El derecho penal hoy. Homenaje al profesor David Baigún (Buenos Aires, del Puerto, 1995).

Pavarini, Massimo, Fuera de los muros de la cárcel: la dislocación de la obsesión correccional, en Bustos Ramírez, Juan (dir.), Prevención y teoría de la pena (Santiago, Editorial Jurídica Cono Sur, 1995)

Prado, Francisco, El sistema penitenciario chileno. Una aproximación critica", en Revista Electrónica Agenda Pública 8 (2006). Prado, Francisco, La crisis en el sistema penitenciario chileno, en Revista Mensaje 503 (2001). 
Racionero, Francisco, El Juez de Vigilancia Penitenciaria: historia de un afán. minorias y prisión en, Eguzkilore 12 (1998).

Roca De Agapito, Luis, La masificación de las cárceles: Breve reflexión a propósito del caso de los Estados Unidos de América, en Revista Electrónica de Ciencia Penal y Criminología 19 (2017), 7.

RODRÍGUeZ yagüE, Cristina, Cuando los centros penitenciarios se convierten en hospitales, psiquiátricos y asilos: aspectos regimentales y tratamentales de la gestión de la enfermedad y la ancianidad en prisión, en Revista General de Derecho Penal 32, IUSTEL. (2019).

Salinero, Sebastián, ¿Por qué aumenta la población penal en Chile? Un estudio criminológico longitudinal, en Ius et Praxis 18 (2012), 1.

SÁnCHEZ, Cristóbal, La aparición y evolución de los sistemas penitenciarios", en Anales de Derecho 31 (2013).

SAnhueza, Guillermo - Pérez, Francisca, Cárceles concesionadas en Chile: evidencia empirica y perspectivas futuras a 10 años de su creación, en Politica Criminal 12 (2017), 24.

Solís, Leslie - De Buen, Néstor - Ley, Sandra, La cárcel en México ¿para qué? (México D.F., México Evalúa, Centro de Análisis de Políticas Públicas A.C., 2013).

Stippell, Jörg, Cárcel, derecho y política (Santiago, LOM, 2013).

STIPPELl, Jörg, Las cárceles y la búsqueda de una política criminal para Chile. Un estudio acerca del acceso a la justicia, la violación de derechos y el nuevo proceso penal (Santiago, LOM, 2006).

Telléz Aguilera, Abel, Novelli y su tiempo. Una aproximación a los origenes y al concepto de Derecho penitenciario, en Revista de Estudios Penitenciario 255 (2011).

Troncone, Pasquale, Manuale di Diritto Penitenziario (Torino, Giappichelli, 2006).

WACQUANT, Loïc, Castigar a los pobres: el gobierno neoliberal de la inseguridad social (Gedisa, Barcelona, 2010).

ZaFfaroni, Eugenio, En busca de las penas perdidas (Buenos Aires, Ediar, 1989).

Zepri, Arianna, La riforma dell'ordinamento penitenziaro, en AmbienteDiritto.It Rivista Giuridica (2005).

ZúNIIGA, Liza, La cárcel enferma: consecuencias para reclusos y vigilantes (Santiago, Serie documentos electrónicos 4, Programa seguridad ciudadana, FLACSO Chile, 2010). 